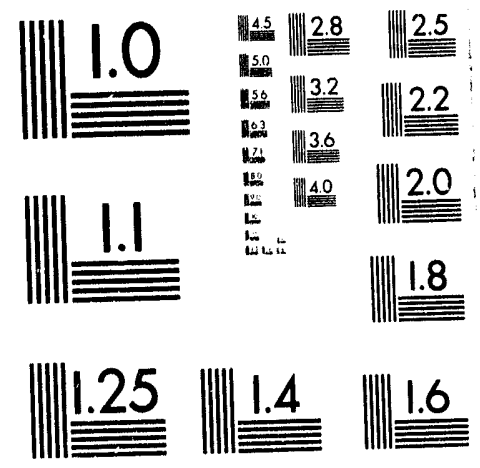



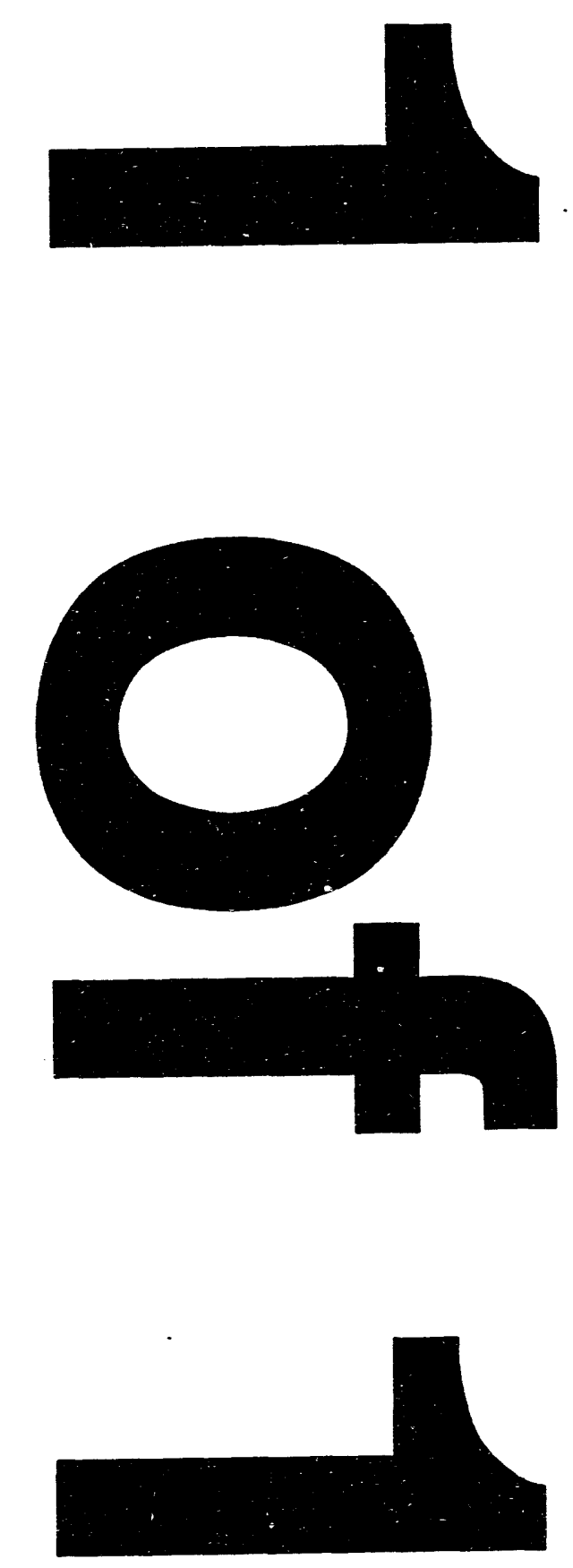


\section{Interim Report on Testing of Off-Gas Treatment Technologies for Abatement of Atmospheric Emissions of Chlorinated Volatile Organic Compounds (U)}




\section{RECEIVEO \\ MAR 141994 \\ WSRC-RP-93-1064 \\ OSTI \\ Rev 0 \\ December 1993}

\section{Interim Report on Testing of Off-Gas Treatment \\ Technologies for Abatement of Atmospheric Emissions of Chlorinated Volatile Organic Compounds (U)}

Prepared by Savannah River Technology Center Environmental Sciences Section

J.S. Haselow, T.R. Jarosch, J. Rossabi, S. Burdick, K. Lombard

D. B. Moore-Shedrow, Section Manager

Authorized Derivative Classifier

Prepared for the U.S. Department of Energy under Contract No. DE-AC09-89SR18035 


\section{DISCLAIMER}

This report was prepared as an account of work sponsored by an agency of the United States Government. Neither the United States Government nor any agency thereof, nor any of their employees, makes any warranty, express or implied, or assumes any legal liability or responsibility for the accuracy, completeness, or usefulness of any information, apparatus, product, or process disclosed, or represents that its use would not infringe privately owned rights. Reference herein to any specific commercial product, process, or service by trade name, trademark, manufacturer, or otherwise does not necessarily constitute or imply its endorsement, recommendation, or favoring by the United States Government or any agency thereof. The views and opinions of authors expressed herein do not necessarily state or reflect those of the United States Government or any agency thereof.

This report has been reproduced directly from the best available copy.

Available to DOE and DOE contractors from the Office of Scientific and Technical Information, P. O. Box 62, Oak Ridge, TN 37831: prices available from (615) $576-8401$.

Available to the public from the National Technical Information Service, U. S. Department of Commerce, 5285 Pon Royal Rd., Springfield, VA 22161 


\section{Contents}

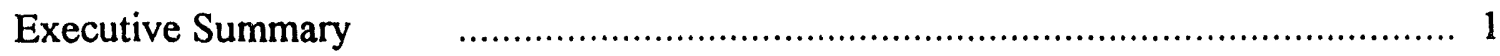

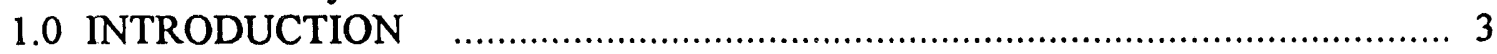

1.1 Technologies Selected for Testing ........................................................ 3

1.2 Destruction versus Conversion................................................................. 4

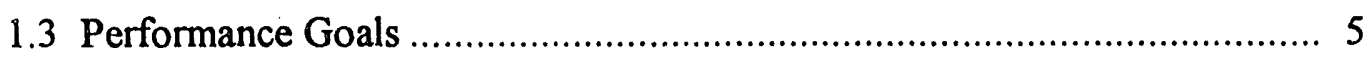

2.0 EXISTING TECHNOLOGIES ……......................................................... 7

2.1 Activated Carbon Adsorption ........................................................... 7

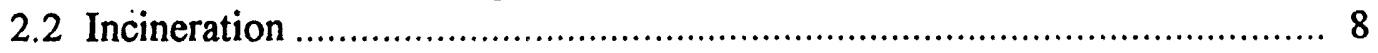

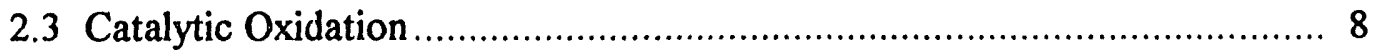

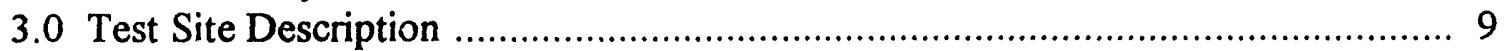

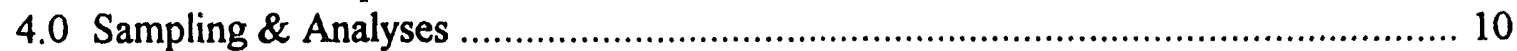

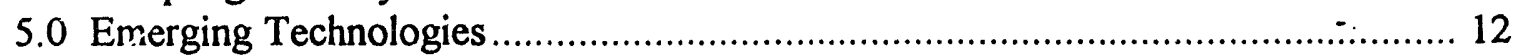

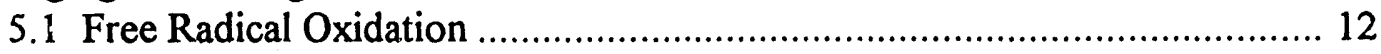

5.1.1 High-Energy Corona ............................................................. 12

5.1.2 Photocatalytic Oxidation .......................................................... 13

5.1.3 Vapor-Phase Photolytic Destruction......................................... 13

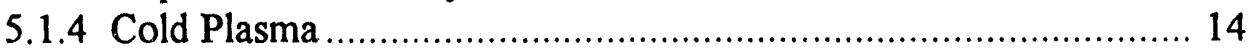

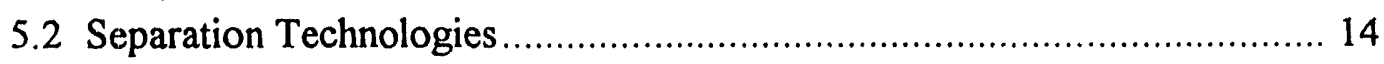

5.2.1 Carbon Regeneration \& Recycling......................................... 14

5.2.2 Gas-Phase Membrane Separation ………………..................... 15

5.3 Biodestruction Technology ................................................................. 15

5.4 Thermal Oxidation T'echnologies............................................................. 16

5.4.1 Carbon Regeneration by Steam Reforming .............................. 16

5.4.2 Pulsed Combustion.................................................................... 16

5.4.3 Thermal Catalytic Oxidation..................................................... 17

6.0 Preliminary Results of Technologies Tested................................................. 18

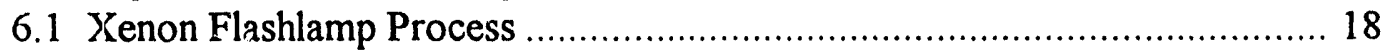

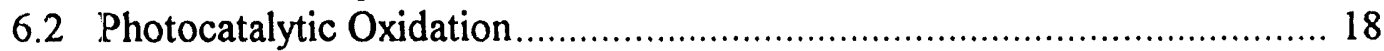

6.2.1 University of Wisconsin ..................................................... 19

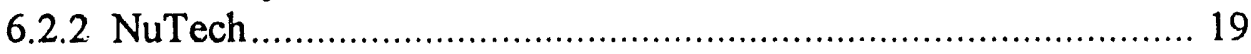

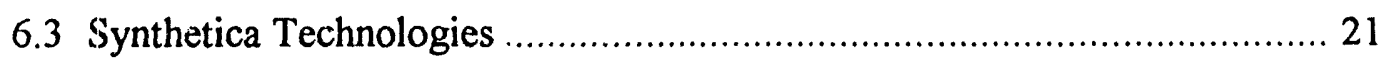

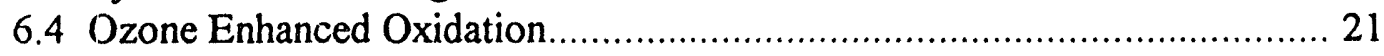

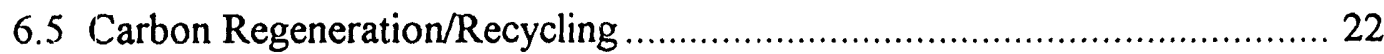

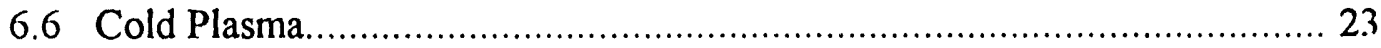

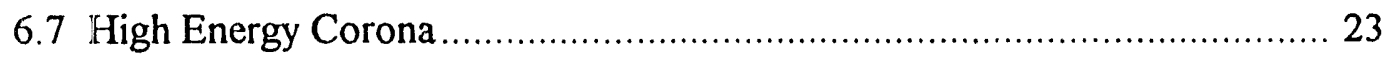

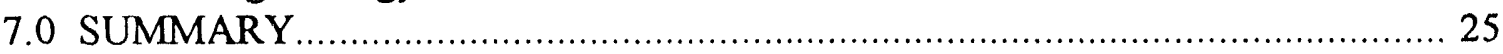

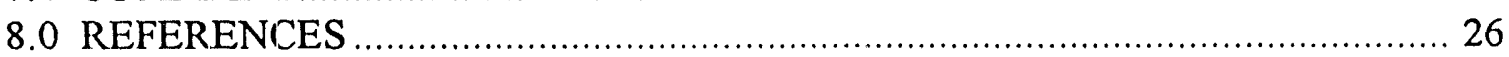




\section{Executive Summary}

Chlorinated volatile organic compounds (CVOCs) are the most pervasive subsurface contaminants within the Department of Energy Complex. The most prevalent remediation technologies for CVOCs ultimately produce a gas-phase stream containing CVOCs, either via vacuum soil venting from the unsaturated zone or ground water recovery from the saturated zone and subsequent airstripping. Many states, including South Carolina, have permitted the direct discharge of the gaseous CVOCs to the atmosphere, where these compounds are decomposed through ultraviolet photolysis. However, the 1990 Clean Air Act Amendments will require that these emissions be abated through the best available technologies. Because of the ubiquity of subsurface CVOC contamination, a modest improvement can provide tremendous benefits over the currently utilized technologies of incineration, catalytic oxidation, and carbon adsorption. This need has motivated the development of diverse technologies for abatement of CVOC emission which may be classified as: free radical oxidation, separation, biodestruction, and thermal oxidation technologies. The Savannah River Technology Center is systematically evaluating several technologies from each of these classes under the Integrated Demonstration Program that is funded by the D.O.E. Office of Technology Development.

The free-radical oxidation processes (high energy corona, cold plasma, photocatalytic oxidation and UV photolysis) are relatively immature in their development process. Early results are encouraging though, as they appear to provide a lower energy process as compared to thermal techniques. Yet, in the authors' opnion, the problem associated with the formation of toxic incomplete decomposition products (such as phosgene, carbon tetrachloride and chloroform) must be solved before these processes can be commercially viable and publicly acceptable.

The thermal catalytic processes are encouraging. When the optimum space velocity and temperature are used, destructions greater than ninety-nine percent are routinely achieved for PCE, TCE, and TCA. At these temperatures, there are slightly detectable amounts of incomplete conversion products. This process will meet the requirements of the Clean Air Act Amendments and will ostensibly be more favorable than activated carbon or incineration. Many sites, including the SRS, are choosing thermal catalytic oxidation for controlling emissions for the soil venting of CVOCs.

The separation processes (membrane separation, carbon adsorption/regeneration) are good for recovering liquid phase CVOCs. There are still problems associated with the collection of water and liability associated with handling the CVOC for recycling. Under current law, the liquid CVOC is considered hazardous waste until an entity purchases the 
solvent for a use. Until it is resold, the generator of the waste is liable.

Off-gas biotechnology processes have not yet been tested at the site. One problem that has emerged during efforts to align the test is that the bioremediation process requires the temperature to be maintained around $20^{\circ} \mathrm{C}$ for conversion of TCE. This means that a controlled environment will be necessary for the process to be robust year round.

A final and more in depth report should be available during September 1994. 


\subsection{INTRODUCTION}

The purpose of this report is to briefly summarize the results to date of the off-gas treatment program for atmospheric emissions of chlorinated volatile organic compounds (CVOCs), in particular trichloroethylene (TCE) and perchloroethylene (PCE). This program is part of the Department of Energy's Office of Technology Development's Integrated Demonstration for Treatment of Organics in Soil and Water at a Non-Arid Site. The off-gas treatment program was initiated after testing of in-situ air stripping with horizontal wells was completed (Looney et al., 1991). That successful test expectedly produced atmospheric enissions of CVOCs that were unabated. It was decided after that test that an off-gas treatment program would complement the Integrated Demonstration not only because off-gas treatment is an integral portion of remediation of CVOC contamination in groundwater and soil but also because several technologies were being developed across the United States to mitigate CVOC emissions. A single platform for testing off-gas treatment technologies would facilitate systematic and unbiased evaluation of the emerging technologies.

Another motivation for the program is that many CVOCs will be regulated under the Clean Air Act Amendments of 1990, and as a result it will be illegal to discharge these compounds directly to the environment by 1995 or 1996, depending upon the compound. Additionally, compounds such as TCE and PCE are pervasive subsurface environmental contaminants, and as a result a small improvement in terms of abatement efficiency or cost will significantly reduce CVOC discharges to the environment as well as costs to United States government and industry.

\subsection{Technologies Selected for Testing}

The main emphasis of this program is on technologies that are being developed in the DOE Complex and by industry teaming with a DOE partner. The participants within the DOE Complex were selected by two separate calls for proposals and reviews. The technologies were selected for demonstration on the basis of technical merit, the ability of the technology to treat contaminants on-site without generating secondary waste, and to represent as wide a variety of technologies as is possible. Two solicitations for proposals were made. The technologies that were selected from the first solicitation, followed in parentheses by the DOE site and the industrial partner, were: steam regeneration of activated carbon (Sandia and Synthetica Technologies), gas-phase bioreactor (Savannah River Technology Center and Ecova), membrane separation (Hanford and Membrane Technology Research), and high-energy corona (Battelle PNL), and from the second solicitation: silent discharge plasma (Los Alamos), xenon flashlamps (Argonne and PURUS), and pulsed combustion (Sandia). Additionally, there was substantial interest in 
attempting to recover the solvents in the soil for recycling so Nucon's thermal desorption of activated carbon and condensation recycle process was also selected for testing in cooperation with Idaho National Engineering Laboratory (INEL), Science Application International Corporation (SAIC), and 3M Inc.

After the selection of the technologies for testing, the off-gas testing program received new guidance, and as a result, a decision was made to first test the membrane separation technology at the Hanford site on carbon tetrachloride in air. Then if the membrane separation test was successful, the technology would be tried at the SRS. Additionally, funding for the gas-phase bioreactor was shifted from OTD funds to internal WSRC funding.

From the beginning, it was recognized that the off-gas testing site might not be fully utilized; therefore, an advertisement was placed in the Business Commerce Daily to solicit other institutions that would be interested in using the test site but with the provision that no direct compensation would be provided. Indirect compensation via the utilities, free use of the test site, and sample analyses are provided at no cost as long as the company is willing to share the data. Through this avenue, NuTech Energy Systems and the University of Wisconsin were identified to test their photocatalytic oxidation systems; Johnson Matthey Inc. for their thermal catalytic oxidation system, and Ultrox Inc. for their ozone oxidation process.

\subsection{Destruction versus Conversion}

Destruction is defined herein as the complete mineralization of CVOCs to carbon dioxide and hydrochloric acid $(\mathrm{HCl})$. Conversion is defined herein as the transformation of the carbon in the inlet CVOC to another product, either carbon dioxide or another organic compound. For example, if a gas concentration was 1000 parts PCE on the inlet side of a treatment process and less than 5 parts on outlet, that would represent greater than 99.5 percent conversion, but would not say anything about percent destruction. If the outlet side had for example 500 parts hexachloroethane and no other organic compounds, then the destruction would only be 50 percent.

A dilemma exists regarding the calculation of converion and destruction. For example, there are (at least) stoichiometrically two reactions that can result in complete oxidation of PCE:

$$
\mathrm{C}_{2} \mathrm{Cl}_{4}+2 \mathrm{H}_{2} \mathrm{O}+0_{2} \Leftrightarrow 2 \mathrm{CO}_{2}+4 \mathrm{HCl}
$$




$$
\mathrm{C}_{2} \mathrm{Cl}_{4}+\mathrm{H}_{2} \mathrm{O}+1.50_{2} \Leftrightarrow 2 \mathrm{CO}_{2}+2 \mathrm{HCl}+\mathrm{Cl}_{2}
$$

In the first reaction above, the PCE is completely mineralized, but in the second reaction the PCE is not completely mineralized even though the carbon is still completely oxidized. Thus; conversion estimates based on $\mathrm{HCl}$ outlet concentrations are tenuous at best. Added to this problem, as one will see, is that often times many other incomplete organic destruction products are formed such as carbon tetrachloride, chloroform, pentachloroethane and hexachloroethane from PCE, for example. When these compounds are produced, from a stoichiometric argument, chlorine may also be produced. Thus, for convenience and for a matter of comparison, percent destruction is the percent of organic carbon that is completely oxidized, and percent conversion is the percentage of inlet contaminant that does not appear on the outlet side. These definitions are convenient because one does not have to measure $\mathrm{HCl}$ and chlorine while the carbon species, provided they are stable and relatively unreactive, can typically be more readily measured with a single analytical instrument, such as a gas chromatograph (GC).

While discussing stoichiometry, it should be noted that water is a reactant and not a product in the oxidation of CVOCs. Often times it is stated that water is an oxidation product, which is assumably an oversite because of an association with the oxidation of fuel-type organic compounds.

\subsection{Performance Goals}

A continuing theme of the OTD program is "better, faster, cheaper, safer" as compared to existing technologies. Faster does not necessarily apply to off-gas treatment because it is limited by removal rates. The existing technologies, which are discussed below, set the standards for comparison regarding better and cheaper. Caution must be exercised when making direct comparisons to existing technologies though, because some technologies are better suited for different process conditions. For example, granular activated carbon (GAC) in fifty-gallon drums is probably not the appropriate existing technology for comparison if the gas stream contaminant mass flux will be greater than 100 pounds per day.

Given that the technology must have some advantages over existing technologies, there are also regulatory driven performance standards that must be met. The performance standards for abatement of new and existing sources are confusing at best, especially when compared to incineration performance standards which essentially state that an incineration facility must attain 99.99 destruction removal efficiency for each principal organic hazardous constituent (40 CFR 264.343). Incineration regulations were not 
intended for other abatement technologies and thus these technologies are subject to the Clean Air Act as amended in 1990 (CAA) and described in Federal Law 71, Section 112.

The CAA performance standards for abatement of particular compounds are poorly defined and subject to interpretation of the "administrator." which in South Carolina would be EPA Region IV or the South Carolina Department of Health and Environmental Control. For example, the CAA states that "sources of hazardous air pollutants shall require the maximum degree of reduction in emissions ... taking into consideration the cost of achieving such emission reduction..." The maximum degree of reduction is defined in two ways: 1) "the average emission limitation achieved by the best performing [process on] twelve percent of the existing sources..." Or essentially, take all the existing or recent sources that are being controlled and take the average percent reduction in emission of the top one-eighth of the performers, or 2) "the average emission limitation achieved by the best performing 5 sources..." As interpreted, the same process could be the best performing on five sources and the average effectiveness of that process would define the performance standard.

There are of course time periods that must be considered and other interpretations that must be made of the law, but the final interpretation of the law is the responsibility of the administrator of the law, which is typically a state regulator. 


\subsection{EXISTING TECHNOLOGIES}

Currently utilized technologies for abating CVOC emissions are: activated carbon adsorption, incineration, and catalytic oxidation (Rinko and Traester, 1988; Buck and Seider, 1991; Adams and Clark, 1991). Each of these methods are useful for a certain range of process variables, i.e. flow rate, contaminant concentration, expected life of operation, etc. Some of the strengths and weaknesses of each of these available technologies are briefly discussed below.

\subsection{Activated Carbon Adsorption}

Activated carbon adsorption is a simple process that is best suited for low flow-rates and moderate concentrations. Higher flow rates and concentrations mandate the use of unmanageable amounts of carbon. For instance, it may take as much as $14 \mathrm{~kg}$ of carbon to adsorb $1 \mathrm{~kg}$ of TCE. When opting for activated carbon, one must choose between using the carbon once, having it regenerated for re-use, or investing in the regenerating equipment. For the proper conditions, the advantages of activated carbon are that it has extremely low capital and operating costs, and the system is easy to set-up. Often, the use of 55 gallons drums of carbon may be suitable. The cost of carbon adsorption can vary greatly depending primarily on regulatory requirements. Typical costs quoted are on the order of $\$ 15 / \mathrm{kg}$. Some of the disadvantages, depending upon whether regeneration is used, are: 1 ) it isn't economical for large flow rates, 2) ultimately one must deal with unregenerable carbon that may be subject to land disposal restrictions, 3) there is shipping, handling and liability associated with regenerating the carbon, 4) there may be additional sampling and analysis requirements for the spent carbon, 5) without regeneration, it is a transfer of CVOC from one phase to another, 6) a heat exchanger may be necessary to operate on a favorable adsorption isotherm (lower temperature), 7) activated carbon is subject to autocatalytic oxidation reactions (fires) that can be stimulated by the heat of adsorption, and 8) water competes for adsorption sites which limits the capacity of the carbon (e.g. Gong and Keener, 1993). Some of the disadvantages of activated carbon may be overcome by investing in an on-site regeneration system, but this will, of course, have strengths and weaknesses.

Some established thermal methods for regenerating activated carbon are infrared heating, incineration or catalysis (Koffskey and Lykins, 1990; Adams and Clark, 1991). Methods that use a heated inert gas to desorb CVOCs from the spent carbon are also available. One advantage of these systems is that the CVOC can be condensed and recycled, provided there is a market for the material. 


\subsection{Incineration}

Incineration, or high-temperature oxidation is a simple technology best suited for streams with relatively high flow-rates and concentrations of CVOC's (see Dempsey and Oppelt, 1993 for a review of incineration technology). The incineration of CVOCs requires a fuel source, and thus can have relatively high energy demands depending upon the concentration of CVOC's in the waste stream. Total costs for incineration are approximately $\$ 2$ to $\$ 6$ per kilogram of CVOC and destruction efficiencies of greater than 99.99 percent can be routinely achieved. Incineration of CVOC's can produce chlorinated products of incomplete combustion (PICS), such as dioxin, as well as hydrochlorir acid and nitrogen oxides. However, the release of these by-products has been successfully controlled in bench scale studies using ammonia injection (Takacs and Moilanen, 1991). One of the main barriers in the use of incinerators for treating waste is public objection. Despite the large amount of technical data available indicating the advantages of incineration over many other methods with respect to destruction efficiency, safety, and cost, the general public adheres to a "not in my backyard" position when a site selection process is initiated. This position is strengthened by the public's increased awareness of environmental issues and some highly publicized environmental catastrophes (Steverson, 1991).

\subsection{Thermal Catalytic Oxidation}

Catalytic oxidation has emerged as an abatement method for CVOC emissions. Although catalytic oxidation is a thermal process, it is not usually viewed as incineration, provided there is not an open flame. Catalysis has lower energy demands than incineration and is better suited for waste streams that have moderate concentrations of CVOCs (Palazzolo et al., 1986; Herbert, 1990; Frost et al., 1991). Destruction efficiencies of greater than $95 \%$ have been achieved. This process previously required frequent recycling or regeneration of the catalyst, because of irreversible chlorine poisoning of the noble metal catalyst (Kittrell et al., 1991); however, a proprietary metal catalyst has been developed and utilized which is not subject to poisoning, yet maintains a high conversion efficiency (Kittrell et al., 1991). As with incineration, treatment of the off-streams from the catalytic process may be needed to neutralize hydrochloric acid that is generated. Additionally, this technology requires energy, but not as much as incineration because operating temperatures are approximately $500 \mathrm{C}$ (versus $900 \mathrm{C}$ for incinera ${ }^{*}$.on). Costs for the destruction of CVOCs with catalysis are comparable to incineration, but catalysis has potentially better regulatory acceptance.

Based on testing at the SRS, catalytic oxidation costs about $\$ 2$ per $\mathrm{kg}$ total based on treating a stream at 180 cubic feet per minute with 800 ppmv of PCE and 900 ppmv of TCE. This is based on preliminary economic analysis and will be more formally presented in the final off-gas treatment report. 


\subsection{TEST SITE DESCRIPTION}

The test site is near the A-014 outfall at the Savannah River Site (SRS) that previously received discharges that contained trichloroethane (TCA), TCE, and PCE. As a result, the soil in the area cuntains these CVOCs. A soil venting well is screened in the vadose zone at this area from 55 to 115 feet below surface. The water table is approximately 116 feet.below surface at the site. A vacuum blower is connected to the well which supplies contaminated air to the processes that are being tested. The contaminated air is passed through a cyclone separator and a filter to remove water and particulates before the gas flows through the treatment process. Activated carbon is used on the end of the system to polish the contaminated stream or serve as a backup in case of a system failure. All processes are connected on the positive pressure side of the vacuum blower so that the $\mathrm{HCl}$ generated by the treatment process will not come in contact with the vacuum blower system.

The vacuum blower generates as much as 11 inches of mercury vacuum on the well and can safely maintain discharge pressures as great as 5 psig. The vacuum blower has a variable drive and the discharge can be passed through a manifold so that flow rates from 5 to 300 scfm can be supplied.

Contaminant concentrations that have been observed are as great as 16,000 part per million by volume (ppmv) for PCE, 2,000 ppmv for TCE, and 400 ppmv for TCA. The air removed through the well is saturated with water at approximately $16 \mathrm{C}$ and is in thermal equilibrium with the soil. The temperature of the contaminated air increases as it passes ihrough the blower to as much as $65 \mathrm{C}$, depending on the ambient air temperature and the pressure drop across the vacuum blower (the air helps cool the blower). Additionally, trace but detectable amounts of chloroform and dichloroethylene have been detected. An air dilution valve is located on the vacuum side of the blower so that these concentrations can easily be reduced. Obviously though, the concentrations are dependent upon the time the vacuum blower has been running, atmospheric pressure, vacuum, etc. so these concentrations are variable. 


\subsection{SAMPLING \& ANALYSES}

Gas phase samples are collected into sampling bags ( 1 liter Tedlar manufactured by Analytical Testing Corporation, PA) on both the inlet and outlet side of the process being tested. The samples are analyzed within four hours after they are taken, but often sooner as the integrity of the sample is compromised with time because of decomposition of the contaminants of concern and absorption onto the sampling bag (e.g. Johnson, 1985). Despite these problems, the samples are believed to be representative. For comparison, during a test of Ultrox's process, an outlet sample was taken with a sampling bag at approximately the same time that an on-line IR analyzer was used. The bagged sample was analyzed with a GC, and both the IR and the GC analyses indicated that the PCE contaminant concentration was approximately $28 \mathrm{ppmv}$. Additionally, during the test of the High-Energy Corona process, PNL had an on-line gas chromatograph for their process. Samples were again taken with bags and analyzed on the GC and they were within five percent of those analyzed with the on-line GC.

A Hewlett Packard 8590A GC with a 60 meter glass capillary column is typically used to analyze the samples. The GC is equipped with both an Flame Ionization Detector (FID) and an Electron Capture Detector (ECD). An integrator is connected to the GC to determine and record the area of peaks for each analysis. The inlet gas samples are typically analyzed with the FID, because the ECD would be overwhelmed by the higher concentrations ( $500 \mathrm{ppmv}$ and greater). The outlet samples are typically analyzed on the same GC with an ECD, because the ECD is significantly more sensitive to chlorinated (electronegative) compounds than the FID and thus has a lower detection level.

The GC is calibrated with standards of $1,10,100$, and 1000 ppmv of compounds of interest. The lower concentration gases are used to calibrate the ECD while the higher concentrations are used to calibrate the FID. A linear regression of the standards analyses is used to estimate the concentrations of actual samples. Calibration standards are always analyzed at least once daily and usually more frequently so that the stability of the GC can be monitored. In addition, the standards are handled in a manner similar to the samples; i.e. the standards are collected and stored in Tedlar bags and analyzed periodically (typically two to three times) over a period of up to 6 to 8 hours. Calibrations are based on the average response of both "fresh" and "aged" standards.

Approximately 10 percent of the samples that are collected are analyzed with a GC connected to a mass spectrometer (GC/MS) using a modified version of EPA SW-846 method 8260A. The GC/MS analyses are used to determine actual compounds in the gas samples, which is of particular importance for the post-process side. The GC/MS provides an order of magnitude estimate of the concentration of the secondary analytes because the 
GC/MS is not calibrated (nor are calibration standards readily available) for many of the decomposition products that are observed for TCE and PCE. 


\subsection{EMERGING TECHNOLOGIES}

The emerging technologies for abatement of CVOC emission can be classified as: free radical oxidation, separation, biodestruction, and thermal oxidation technologies. Each of these methods have strengths and weaknesses that are summarized below. Rossabi et al., 1991 and Haselow et al., 1992 also provided a review of emerging technologies for off-gas treatment.

\subsection{Free Radical Oxidation}

Free-radical oxidation refers to technologies that utilize some energy source to create reactive free radicals that can be easily oxidized or reformed to simpler products. Free radicals refer to a bond that is broken and leaves an unpaired electron. Free radicals can be created by bombarding a molecule with electrons created by electrical discharges or by exciting electron bonds with some form of energy, such as high-frequency light or electron beams. With free-radical oxidation of CVOCs, water vapor is broken down to hydrogen and hydroxyl radicals, the latter of which is an excellent oxidizing agent. At the same time, carbon-chlorine bonds and carbon-carbon bonds are cleaved to form free radicals. It is the goal of the free-radical oxidation process to have the free-radicals recombine to form $\mathrm{HCl}$ and carbon dioxide, but unfortunately, the free radicals that are created from the CVOCs often recombine to form more toxic compounds some of which are more difficult to mineralize than the original CVOC.

Nunez et al. (1993) provide an excellent discussion of free-radical oxidation mechanisms and theory from a corona destruction technology viewpoint, but their discussion is applicable to most if not all free-radical oxidation processes. They also indicate in that paper that the ionization potential of the CVOC is an indicator of the compounds ease of destruction by free-radical oxidation.

\subsubsection{High-Energy Corona}

This technology uses several nonconductive electrodes within a glass tubular reactor to create a low-temperature plasma (Nunez et al., 1993). The plasma is created as the electrodes discharge and partially ionize the gas within the reactor. In other words, the electrical field forces current to flow by stripping electrons off neutral gas molecules. The electrons discharged are highly reactive and enhance the reaction of TCE and PCE. The advantages of this technology are that no heating, additives, or catalysts are required and the energy consumption is relatively low. The disadvantage is that it is unproven for treatment of high-flow rate streams required for field demonstration and phosgene is sometimes formed (Heath, 1992, personal communication). 
Battelle Pacific Northwest Laboratory (PNL) developed a high-energy corona system that was tested at the SRS. The test unit processed flow rates from 25 to $50 \mathrm{scfm}$ and CVOC concentrations from 500 to $4000 \mathrm{ppmv}$ total.

\subsubsection{Photocatalytic Oxidation}

Photocatalytic oxidation refers to a process in which a contaminant is oxidized by free radicals formed from the interaction of light and oxidizing agents such as ozone, hydrogen peroxide, or a catalyst, such as titanium dioxide. The photocatalytic oxidation process typically uses an ultraviolet (UV) light source and one or a combination of the oxidizing agents or catalysts listed above. For organic compounds such as TCE or PCE, the oxidation process is actually multifaceted. The contaminant can be destroyed by direct photolysis through the molecular absorption of UV light, by interaction of the contaminant with the oxidant, by the oxidation of the contaminant by free radicals formed from photolysis of the oxidant, or interaction of the two oxidants such as ozone and hydrogen peroxide (Glaze et al., 1987; Ollis et al., 1991). The production of free radicals is the dominant mechanism in these systems (Glaze et al., 1987; Peyton and Glaze, 1988; Glaze and Kang, 1989a; Glaze and Kang, 1989b). Most work in this area has been done using an aqueous waste stream; however, for surface site interactions such as titanium-dioxide mediated processes, a vapor phase waste stream should be mitigated at similar if not increased rates due to a lower concentration of radical scavengers. Some common scavengers in natural waters are inorganic carbon species and natural humic substances (Zafiriou, 1977; Fischer et al., 1987; Glaze and Kang, 1989b). Two advantages of this process are low capital costs anc' low operating costs while maintaining high destruction efficiencies.

The University of Wisconsin, NuTech Energy Systems, and International Technology (IT) Corporation are all investigating photocatalytic oxidation of CVOCs using a titanium dioxide catalyst and ultraviolet light. Both processes have differences in the way the catalysts or the light source is employed. The University of Wisconsin and NuTech processes were tested at the SRS. The University of Wisconsin system processed flows up to 10 liters per minute, and the NuTech system processed flows up to $75 \mathrm{scfm}$. The CVOC concentration was from 1000 to 5000 ppmv.

\subsubsection{Vapor-Phase Photolytic Destruction}

CVOCs undergo photolysis when exposed to the proper electromagnetic frequency corresponding to the intramolecular bonding energy of the CVOC. The electromagnetic energy in this process can be supplied by any source that emits within the absorption band of the target contaminant. TCE has an absorption band that centers around $230 \mathrm{~nm}$. 
Traditionally used sources have been mercury vapor lamps (Wekhof, 1991) which have a strong but relatively narrow banded output at $254 \mathrm{~nm}$. These sources were used in water treatment advanced oxidation processes with hydrogen peroxide or ozone, which have absorption bands in the vicinity of $254 \mathrm{~nm}$ leading to the formation of free radicals. The target contaminant would therefore be predominantly oxidized by the free radicals formed rather than by direct photolysis since the $254 \mathrm{~nm}$ line is on the fringe of the TCE absorption band. The oxidation of the contaminant in this situation would depend on its refractivity and the refractivity of its intermediate breakdown byproducts to free radical attack. In contrast, a broad band UV source would have the advantage of supplying energy in the absorption bands of several contaminants as well as their intermediate photolytic byproducts (Wekhof, 1991). This would ensure a complete mineralization of the contaminant by successive photolytic reactions. Promising sources for broad band UV output are commercially available and custom built, pulsed xenon sources.

Purus Inc. developed a vapor-phase photolytic process for destruction of CVOCs that utilize xenon flashlamps that flash at frequencies from 3 to $32 \mathrm{~Hz}$. One system they developed can treat flow rates as high as $250 \mathrm{cfm}$. Their technology was tested at the SRS with support from Argonne National Laboratory.

\subsubsection{Cold Plasma}

The cold plasma or "silent discharge" process is very similar to the high-energy corona process except that the electrical potential is pulsed at higher frequencies and the discharge occurs across parallel rectangular plates. Los Alamos National Laboratory (LANL) developed a cold plasma treatment system that was tested at the SRS. The system treated flow rates in the range of 30 to 95 standard liters per minute and concentrations of CVOCs from 700 to 4000 ppmv.

\subsection{Separation Technologies}

With separation technologies, the gas-phase CVOCs are ultimately collected as a liquid phase that can either be destroyed in a concentrated form or recycled. A market currently still exists for TCE and PCE. Separation technologies can be direct condensation, or adsorption and desorption followed by condensation, or direct membrane separation.

\subsubsection{Carbon Regeneration \& Recycling}

With this process, the off-gas is cooled to approximately $25 \mathrm{C}$ to increase adsorption onto activated carbon. The gas is passed through the carbon until breakthrough. Then the $\mathrm{CVOC}$ is desorbed from the carbon with hot nitrogen gas and most of the water in the 
original gas stream remains on the hydrophilic carbon. With NuCon's process, the nitrogen gas is cooled and heated with a Brayton refrigeration cycle. During the cooling (or expansion part) of the cycle, the CVOC is condensed from the gas stream and is collected for recycling. NuCon's Braysorb has been successfully utilized to recycle solvents at manufacturing facilities where the solvent is used in the process by companies such as $3 \mathrm{M}$. Purus Inc. also has a similar process that uses a Rankine refrigeration cycle, but the NuCon process was tested as part of this program. The NuCon system tested can treat flow rates

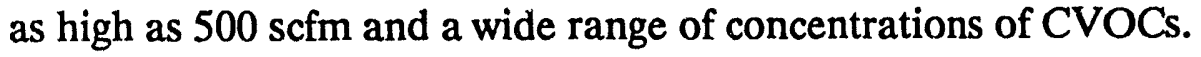

\subsubsection{Gas-Phase Membrane Separation}

Gas-phase membrane separation is a mature technology where gas-phase components are selectively separated as they flow through a specially designed membrane (Wijmans et al., 1990). Membrane Technology Research Inc. teamed with the Westinghouse Hanford Company to develop a process for the removal of carbon tetrachloride. The disadvantage is that the current technology is more expensive than existing technologies, such as refrigeration cycles, mainly because the currently available membranes can only remove a fraction of the TCE or PCE from the waste stream per cycle thereby requiring multiple cycles and the gas must be compressed to high pressures to pass through the membrane.

This membrane separation process was not tested at the SRS, but was going to be considered if it was successful at Hanford.

\subsection{Biodestruction Technology}

A gas-phase bioreactor will be used to aerobically break down TCE to carbon dioxide and chloride ions. The reactor will use a packed bed consisting of ceramic beads on which a biofilm will be maintained. Indigenous organisms capable of co-metabolizing TCE will be developed. The advantage of this system is that the operating costs are minimal and no hazardous byproducts are produced. The disadvantages include maintaining a viable biofilm, the requirement of long residence times, and that the temperature must be maintained around $20^{\circ} \mathrm{C}$ so that for environmental applications a controlled environment is necessary. Work on similar technology has been done in the treatment of groundwater contaminated with TCE (e.g. Strandberg et al., 1989).

The test of this technology will be completed by the Savannah River Technology Center and Ecova Inc. during the spring 1994. Ecova will treat a stream of approximately $10 \mathrm{cfm}$ with a total CVOC concentration of 1000 ppmv. 


\subsection{Thermal Oxidation Technologies}

With thermal oxidation technologies, the CVOCs in the gas phase are oxidized with the oxygen in the air. The direct oxidation typically occurs at temperatures above $700^{\circ} \mathrm{C}$, such as with incineration. By adding catalyst, the oxidation temperature can be reduced to as low as $450{ }^{\circ} \mathrm{C}$. These technologies are typically not considered incineration because they are not oxidized with an open flame (burning, such as with an incineration) and/or the process does not rely on radiative heat.

\subsubsection{Carbon Regeneration by Steam Reforming}

TCE and PCE are removed from a gas stream by adsorption on granular activated carbon and are later desorbed by passing $260 \mathrm{C}$ steam over the activated carbon. The CVOCladen steam is passed through a moving-bed reactor, that is packed with ceramic spheres that are coated with a slurry base. In the reactor, which operates at $700 \mathrm{C}$, the CVOCs are dechlorinated. The reactor creates hydrochloric acid that is neutralized by the slurry base. The $\mathrm{HCl}$ depleied stream from the reactor is sent to a steam reforming reactor, which operates at $1500 \mathrm{C}$, where all the undestroyed organic materials are completely mineralized to $\mathrm{CO}_{2}$ and $\mathrm{H}_{2}$. The advantages of this technology are: 1) the system is portable, 2) the system is suited for 55 gallon drums of carbon, 3) operating costs are estimated to be about \$1 per kg of CVOC, 4) 99.99 percent destruction efficiencies have been achieved, 5) all emissions from the system meet air quality standards, and 6) a significant fraction of the $\mathrm{HCl}$ is neutralized without having to use a post-treatment scrubbing process. Disadvantages are that it requires high operating temperatures with streams that contain $\mathrm{HCl}$, so expensive materials of construction may be necessary and the fuel costs may be prohibitive. Also, a fraction of the carbon is consumed each time in the regeneration process.

Drums of activated carbon for this test were loaded at the SRS with TCE and PCE and shipped to the Synthetica Technologies Inc. in California for testing.

\subsubsection{Pulsed Combustion}

This process uses a two stage thermal destruction method involving rapid fluid dynamic mixing in the combustion chamber and acoustic resonance to increase mass transport to the catalyst material (Keller et al., 1990). . Destruction efficiencies in excess of $99 \%$ have been achieved with methyl ethyl ketone. Work with this technology has concentrated on making thermal catalytic oxidation more energy efficient. 
Sandia National Laboratory has cooperated with Engelhard on developing this technology. The system they are developing will treat flow rates up to $100 \mathrm{cfm}$.

\subsubsection{Thermal Catalytic Oxidation}

Thermal catalytic oxidation utilizes a fixed bed of noble metal catalyst at temperatures from 450 to $550^{\circ} \mathrm{C}$. The catalyst compositions are proprietary. Johnson Matthey, Engelhard, and Allied Signal are currently manufacturing catalyst for CVOCs. Flow rates are determined by the amount of catalyst and the required residence time for destruction of the CVOC.

Tests of a Johnson Matthey catalyst have been completed at the SRS. Commercial off-gas treatment units employing the Allied Signal catalyst have been used successfully at SRS to control emmisions during tests of in-situ enhanced remediation technologies. 


\subsection{PRELIMINARY RESULTS OF TECHNOLOGIES TESTED}

Below are brief summaries of the results of the technologies that have been tested as part of the off-gas treatment program at the SRS. A more detailed analysis of the technologies will be provided in the final testing report and in individual reports for each of the technologies. Also, Los Alamos National Laboratory is completing an economic analysis of each of the technologies that will be included in the final off-gas treatment report, which should be completed by August 31, 1994.

\subsection{Xenon Flashlamp Process}

The test of the Purus Xenon flashlamp process was completed during March and April 1993. The tests showed that TCE is effectively converted at or beyond flashlamp frequencies of $3 \mathrm{~Hz}$, and $\mathrm{PCE}$ is converted at frequencies above $5 \mathrm{~Hz}$. These conversions were noted for all flow rates and inlet concentrations.

The percent destruction has not been estimated yet. Incomplete decomposition products such as chloroform (trichloromethane or $\mathrm{CF}$ ), carbon tetrachloride (CT), phosgene, dichloroacetic acid (DCAA), pentachloroethane (PCA) and hexachloroethane (HCA) were detected in the outlet. CT concentrations were less than 15 ppmv. Many of these compounds are more toxic than the original components. Additionally, TCA that was in the inlet in lower concentrations usually went through unchanged. This is probably because TCA has all single bonds (and higher ionization potential) which makes it more difficult for the free radical oxidation process to be initiated. This also does not bode well for the free radical oxidation processes because many of the incomplete decomposition products are single bond compounds, such as CF, CT, PCA, and HCA.

\subsection{Photocatalytic Oxidation}

Two photocatalytic oxidation processes were tested at the SRS; the University of Wisconsin (UW) and the NuTech processes. The UV light excites electrons in the titania (anatase) inducing an electron-hole pair. The electrons and holes serve as sites for the production of reactive ions and free radicals which oxidize the trichloroethylene (TCE) and perchloroethylene (PCE) to carbon dioxide and hydrochloric acid. There are several differences between the two processes. First, the UW process uses a mildly sintered sol-gel of titanium dioxide with a higher specific surface area $\left(150\right.$ to $300 \mathrm{~m}^{2} / \mathrm{g}$ versus $50 \mathrm{~m}^{2} / \mathrm{g}$ for commercial grade titania), while the NuTech process uses a fiber support material for commercial grade titanium dioxide. Second, the UW reactor is temperature controlled with typ cal operation occuring at temperatures of 50 to $100 \mathrm{C}$. Third, the Nutech process uses commercial tanning lamps which emit higher frequency (UV-A) radiation; the UW system employs standard black lights. In addition, the University of Wisconsin initially 
modified the water vapor content of the feed gas by passing the stream through a condenser at $0{ }^{\circ} \mathrm{C}$ (a second test with a larger scale unit did not incorporate water vapor control). While water is a necessary reactant in the oxidation mechanism, high humidity can result in excess adsorbed water blocking reactive sites on the catalyst surface. If control of water vapor is required, consideration must be given to the disposition of the secońdary waste stream generated.

\subsubsection{University of Wisconsin}

A portable laboratory-scale unit was tested in the field over a five day period in June of 1992. The test reactor, an annular packed bed design, was operated at 55 to $60^{\circ} \mathrm{C}$ with data collected at three different flow rates $(40,100$, and $200 \mathrm{cc} / \mathrm{min})$ over a continuous operation time of roughly 72 hours. The inlet gas-phase CVOC concentrations exhibited apparent diurnal fluctuations over the course of testing with levels ranging from 1900 - 7000 ppmv of PCE, 222 - 1100 ppmv of TCE, 64 160 ppmv 1,1,1-TCA, and 30 - 55 ppmv 1,1-DCE. The conversion efficiency following an initial 24 hour equilibration period varied from 97 to 100 percent for TCE and from 88 to 99.9 percent for PCE. 1,1,1-TCA did not appear to be converted in the process. The only intermediate products detected were carbon tetrachloride (typically 40 to $100 \mathrm{ppmv}$ ) and chloroform (typically less than 10 ppmv). These concentrations represent molar conversions of approximately 2 percent to carbon tetrachloride and 0.2 percent to chloroform. Due to the unavailability of on-line or at-line analysis, there was no conclusive evidence to confirm the presence of other intermediates. The detection of carbon tetrachloride and chloroform suggest the likelihood of a chlorine radical addition mechanism which has been identified as a possible pathway for the formation of DCAC and phosgene by other research groups (Nimios et al, 1993). A second field test of a larger scale system was conducted in November of 1993. This second test included the use of at-line GC/ECD/FID analysis and on-line wet chemical methods for the derivatization and stabilization of reactive intermediates. The results of the test are currently being analyzed.

\subsubsection{NuTech}

The NuTech system consists of 72 annular tube reactors. Each tube consists of a fiberglass-mesh coated titania catalyst wrapped around an ultra violet lamp. The reactor was run in a dual pass mode (36 tubes per pass) at flow rates from 12 to 55 scfm.

The samples for these experiments were taken approximately one hour after the flow rate was established. Earlier experiments with shorter "equilibration" times 
gave inconsistent results. The fraction of TCE and PCE converted was inversely proportional to the flow rate, suggesting a residence time effect. Conversions ranged from 50 to 99 percent with the conversion of TCE consistently greater than that for PCE. The soil contaminants also include small concentrations of 1,1dichloroethylene (1,1-DCE) and trichloroethane. The 1,1-DCE was converted similar to TCE and PCE. However, the TCA was not affected by the system. This finding is consistent with results in the literature on the difficulty of destroying the saturated chloroethanes with photocatalytic methods. The results from these tests also revealed that as the conversions increased, the levels of detected side products also increased. Chloroform and carbon tetrachloride were detected in all of the first-pass and outlet samples. The GC was not calibrated for CF and CT at the time of testing. Nonetheless, sufficient quantitative information can be obtained from the relative changes in peak area from half and full pass and from one flow rate to another. Both CF and CT are not destroyed by photocatalysis.

Additional side products identified by NUTECH in previous testing include pentachloroethane and hexachloroethane. These products were also identified in a previous test conducted in May and in a field test of a smaller photocatalytic system being developed at the University of Wisconsin. It is suspected that these polychorinated side products are indicative of the presence of molecular chlorine or chloride radicals. Small quantities of methylchloroformate, a derivative of phosgene obtained from bubbling trapped samples through methanol, were detected in two of the outlet samples with the GC/MS. No calibration data for the derivatization of phosgene with the GC-MS are available.

The results from this and previous testing of photocatalytic systems at SRS can be summarized as follows:

(1) The gas-phase photocatalytic systems are capable of "converting" TCE, PCE, and 1,1-DCE with efficiencies greater than $90 \%$ at a sufficient residence time (low flow rate).

(2) The gas-phase photocatalytic systems produce a number of chlorinated side products which are not subsequently destroyed in the process. The concentrations of these side products increase with an increase in the conversion of TCE and PCE. The analysis to date has confirmed the production of readily measurable quantities of chloroform and carbon tetrachloride. Lesser products include PCA and HCA. Small quantities of methylchloroformate, a derivative of phosgene, and trichloroacetaldehyde have been detected in some samples from the NUTECH tests. 


\subsection{Synthetica Technologie's Carbon Regeneration}

Drums of activated carbon were loaded and shipped to Synthetica in April 1992. Synthetica has not completed tests on the drums of activated carbon because of operating problems with the process which is mainly associated with materials of constructions. At high temperatures, the $\mathrm{HCl}$ is extremely corrosive.

\subsection{Ozone Enhanced Oxidation}

During the January 1993 demonstration at the SRS, the contaminants were evacuated from the soil by the use of the blower in the Ultrox system. The influent vapors were diluted with outside air by a control valve which was installed at the vapor inlet. The vapor concentration was controlled by air dilution in a range of 100 up to 2,000 ppmv. PCE was the major contaminant consisting of over $90 \%$ of the total vapor influent. The remainder of the chlorinated solvents were TCE and TCA. The samples that were taken and analyzed showed that the main by-product other than hydrogen chloride was carbon tetrachloride. When the ozone to VOC ratio was below 1:1 weight to weight(w/w), additional by-products were formed such as chloroform, pentachloroethane, and hexachloroethane.

In addition to the ozone to $\mathrm{VOC}$ ratio, humidity played a minor role in the formation of the by-products. The overall destruction efficiency did not change over a wide range of humidity content in the influent vapor. However, when the influent vapor was oversaturated with water, there was an increase in the by-products formation. (The site was located outside and due to the drastic weather changes, mist was mixed in with influent stream.) During the pilot study, the analytical data showed a tentatively identified compound trichloronitromethane (TNM) at an approximate concentration of 0.7 to 7 ppmv. Possibly, TNM was formed when the ozone generator cooling water was running 20 to $30 \mathrm{~F}$ higher due to a chiller failure. In addition, a leaky flex hose was connected from the blower to two carbon drums in series. The VOCs from the leaky hose could at times be picked-up by the air compressor, and this might have formed the TNM in the dielectrics within the ozone generator. (A pilot demonstration in Michigan detected no TNM as a byproduct.)

When CVOCs react with ozone in the catalyst bed, it is possible to form phosgene as a byproduct. The phosgene was monitored by bubbling phosgene in metharol solution to form methychloroformate. Phosgene was detected below the standard reporting limit of $0.5 \mathrm{ppb}$ (mass by volume) when the Ultrox process was treating over $6,000 \mathrm{ppb}$ (mass by volume) of TCE and PCE. A more sensitive and accurate method (EPA Method T06) for analyzing phosgene was used at a Michigan site demonstration. With a method detection limit of 0.1 
$\mathrm{ng} / \mathrm{L}$ (mass by volume), the phosgene concentration was $9 \mathrm{ng} / \mathrm{L}$ (mass by volume) at the Michigan test site.

Therefore, by controlling the ozone ratio in the Ultrox system, the by-product formation can be minimized. Whenever the ozone is in excess, there is an increase in the system performance.

\subsection{Carbon Regeneration/Recycling}

The NUCON pilot plant was operated in the field over a two week period in April 1993. The typical gas-phase concentrations for PCE and TCE during operation were 6000 - 7000 ppmv and 500 to 1000 ppmv, respectively. To extend the breakthrough time for the carbon beds at these high concentrations, a $75 \mathrm{scfm}$ stream was used (the pilot unit is capable of handling flows up to $250 \mathrm{scfm}$ ). The test involved six adsorption-regeneration cycles with breakthrough times varying from 10 to 13 hours and regeneration times requiring approximately 4 hours. A total of approximately 500 pounds of solvent were recovered. In addition, nearly 50 pounds of water was also collected, although the bulk of this secondary waste was recovered in the pre-chiller for the carbon beds. The pre-chiller is normally used to lower the inlet temperature of the solvent laden gas stream fed to the carbon beds to enhance adsorption capacity. However, at the high inlet solvent concentrations particular to the test well and at the high relative humidity generally encountered with soil vacuum extraction feed streams, use of the pre-chiller led to the direct condensation of solvent and water vapors and, therefore, was not used after this discovery made during the first cycle. The working capacity of the carbon beds ( 200 pounds each) was 46.5 percent with a recovery efficiency greater than 97 percent. Due to the relatively low vapor pressures of PCE and TCE at the typical operating temperatures of the brayton cycle $\left(-20\right.$ to $\left.-100^{\circ} \mathrm{C}\right)$, the majority of solvent ( $>99$ percent) was recovered in the first separator following initial cooling and prior to the expansion of the recycled gas stream. An additional discovery made during the test involved the potential for cross-contamination of waste streams processed by a de-coupled recovery unit (e.g. dedicated carbon beds regenenerated with a leased or purchased mobile recovery unit). This potential was apparent by the detection of toluene (and trace quantities of xylenes) in the recovered solvent and in gas analyses made at the process lines feeding and exiting the carbon beds. These residual solvents were retained in the system from a test of the unit prior to its arrival at the SRS.

The composition of the material collected (as determined by GC/MS) was 458 pounds PCE, 48 pounds water, 36.4 pounds TCE, 3 pounds toluene, and 1.6 pounds 1,1,1trichloroethane. The toluene and water were undesirable components of the collection, because the water would need to be separated frorn the mixture and toluene is combustible and explosive. 


\subsection{Cold Plasma}

A test of the Cold Plasma technology was completed during September and October 1993. The field tests demonstrated that TCE is easiest to treat, PCE is next easiest, and TCA is the most difficult to treat. Conversions of greater than $99 \%$ were obtained for TCE over a broadrange of energy density ( 3.71 to $16.14 \mathrm{~J} / \mathrm{cm} 3$ ), concentrations, and flow rates. PCE conversions were also greater than $99 \%$ over the whole range of test parameters. The best conversion achieved for TCA was about $98 \%$ at $13.98 \mathrm{~J} / \mathrm{cm} 3$. The mineralization of the VOCs is incomplete as about 20 small incomplete decomposition products (probably each $<1 \mathrm{ppm}$ ) were observed for most of the runs. Representative chlorocarbon byproducts identified were the input CVOCs (PCE, TCA, TCE), as well as CT, CF, DCAC, trichloracetic acid (TCAA), and phosgene (which is easily destroyed by the water scrubber). The partitioning of these byproducts and the absolute concentrations have not yet been determined. This is being examined and will be further discussed in later reports. The achieved conversion for total CVOCs (PCE, TCA, TCE) is certainly greater than the 95\%, but the destruction has not been estimated. It will be evaluated whether the byproducts resulting from the conversion of VOCs into other chlorocarbons approaches or exceeds air emissions limits.

Also during the test, it was observed that the power delivered into the gas was generally around 6 to $7 \mathrm{~kW}$ with about 15 to $17 \mathrm{~kW}$ of wall-plug power. The power supply is about 75 to $80 \%$ efficient and slightly more than one-half of the power supply output was delivered into the gas; most of the remainder went to dielectric losses in the Pyrex (the dielectric used to !ine the plates). The driver circuit was also not optimum for the load. Many factors affect circuit performance; some of which were unknown until actual operation.

The partial pressure of water vapor from the well remained fairly constant around 12 Torr until the final run day where it dropped to 8 Torr (It was a cold day and some water may have condensed out in the well piping.). This occurred during the low flow rate runs where the well gas was diluted with cold atmospheric air. There appears to be a good correlation between water vapor concentration and ease of destruction. For four runs with only 8 Torr of water vapor present and at the higher cell energy densities $(269,110,226$, and 233 $\mathrm{W} /$ liter/min, respectively), the conversion is less, which may indicate less water vapor is yielding lower hydroxyl radical concentrations.

\subsection{High Energy Corona}

The High Energy Corona (HEC) process was tested during May 1993. Greater than 99 percent conversions for PCE and TCE were obtained during the HEC testing. As expected, with increasing residence time the percent conversion increased. PCE required a 
nearly three fold greater residence time than TCE to achieve 99 percent conversion.

As relative humiuity of the inlet gas increased, the incomplete decomposition products and required power input increased while the conversion efficiency decreased. This is speculated to occur because more power is required and consumed by the conversion of water to hydroxyl and hydrogen radicals.

As might be expected, the total amount of byproducts varied inversely with reactor residence time. At all residence times, less than 3 ppmv of trichloronitromethane, TCAA, PCA and HCA were detected in the effluent. CF and CT concentrations varied between 5 to 10 ppmv. DCAA was suspected to be in the off-gas but was not detected because an ion chromatograph was not used in the analyses. Chloromethane, methylene chloride, and TCA were also detected in the effluent. However, concentration estimates of chloromethane and methylene chloride are not available. TCA is most likely from influent and passed through the system nearly untreated.

PNL is applying for a patent for their HEC process, and as result much of the detail has been withheld from this report. 


\subsection{SUMMARY}

The free-radical oxidation processes are relatively immature in their development process. Early results are encouraging though as they appear to require less energy than thermal processes. Yet the problem associated with the formation of toxic incomplete decomposition products must be solved before these processes can be commercially viable and publicly acceptable, in the authors' opinion.

The thermal catalytic processes are encouraging. When the optimum space velocity and temperature are used, destructions greater than ninety-nine percent are routinely achieved for PCE, TCE, and TCA. At these temperatures, there are slightly detectable amounts of incomplete conversion products. This process will meet the requirements of the Clean Air Act Amendments and will ostensibly be more favorable than activated carbon or incineration. Many sites, including the SRS, are choosing thermal catalytic oxidation for controlling emissions for the soil venting of CVOCs.

The separation processes are good for recovering liquid phase CVOCs. There are still problems associated with the collection of water and liability associated with handling the CVOCs for recycling. Under current law, the liquid CVOC is considered hazardous waste until an entity purchases the solvent for a use. Until it is resold, the generator of the waste is liable.

Off-gas biotechnology processes have not yet been tested at the site. One problem that has emerged during efforts to align the test is that the bioremediation process requires the temperature to be maintained around $20^{\circ} \mathrm{C}$ for conversion of TCE. This means that a controlled environment will be necessary for the process to be robust year round.

A final and more in depth report should be available during September 1994. 


\subsection{REFERENCES}

Adams, J.Q., and Clark, R.M., Evaluating the Costs of Packed-Tower Aeration and GAC for Controlling Selected Organics, Journal AWWA, 83, No.1, 49-57, 1991.

Alpert, D.J., Sprung, J.L., Pacheco, J.E., Prairie, M.R., Reilly, H.E., Milne, T.A., and Nimlos, M.R., Sandia National Laboratories' Work in Solar Detoxification of Hazardous Wastes, SAND--90-0935C DE90 016106, 1990.

Basta, N., The Recycling Loop Closes for Solvents, Chem. Eng, 98, No.12, 23-29, 1991.

Buck, F.A.M., and E.L. Seider, Commercial Vapor Treatment Processes, Paper Presented at Symposium on Soil Venting, Houston, TX, April 29 to May 1, 1991. (Páper may be obtained from King, Buck \& Associates, Inc., San Diego, CA)

Cheung, H. M., Bhatnagar, A., and Jansen, G., Sonochemical Destruction of Chlorinated Hydrocarbons in Dilute Aqueous Solution, Environmental Science and Technology, 25, $1510-1512,1991$.

Chozick, R., and Irvine, R.L., Preliminary Studies on the Granular Activated CarbonSequencing Batch Biofilm Reactor, Environmental Progress, 10, 282-289, 1991.

Dempsey, C.R. and Oppelt, E.T., Incineration of Hazardous Waste: A Critical Review Update, J. of Air \& Waste Management, 43, 25-73, January, 1993.

DeWaters, J.E., and DiGiano, F.A., The Influence of Ozonated Natural Organic Matter on the Biodegradation of a Micropollutant in a GAC Bed, Journal AWWA, $\underline{82}$, No.8, 69-75, 1990.

Fischer, A.M., Winterle, J.S., and Mill, T., Primary Photochemical Processes in Photolysis Mediated by Humic Substances, Photochemistry of Environmental Aquatic Systems, American Chemical Society, 1987.

Frost, A.C., Sawyer, J.E., Summers, J.C., Shah, Y.T., and Dassori, C.G., Kinetics and Transport Parameters for the Fixed-Bed Catalytic Incineration of Volatile Organic Compounds,Environmental Science and Technology, 25, 2065-2070, 1991.

Glaze, W.H., and Kang, J.W., Advanced Oxidation Processes. Description of a Kinetic Model for the Oxidation of Hazardous Materials in Aqueous Media with Ozone and Hydrogen Peroxide in a Semibatch Reactor, I\&EC Research, 28, 1573-1580, 1989a. 
Glaze, W.H., and Kang, J.W., Advanced Oxidation Processes. Test of a Kinetic Model for the Oxidation of Organic Compounds with Ozone and Hydrogen Peroxide in a Semibatch Reactor, I\&EC Research, 28, 1580-1587, 1989 b.

Glaze, W.H., Kang, J.W., and Chapin, D.H., The Chemistry of Water Treatment Processes Involving Ozone, Hydrogen Peroxide and Ultraviolet Radiation, Ozone Science \& Engineering, 9, 335-352, 1987.

Gong, R., and Kenner, T.C., A Qualitative Analysis of the Effects of Water Vapor on Multi-Component Vapor-Phase Carbon Adsorption, J. Air \& Waste Management, 43, 864872, June, 1993.

Haselow, J.S., J. Rossabi, T.R. Jarosch, 1992. Emerging Technologies for Abatement of Atmospheric Chlorinated Volatile Organic Compound Emissions, Proceedings of the 1992 Waste Management and Environmental Sciences Conference, San Juan Puerto Rico, April 9-11, 1992.

Herbert, K.J., Catalysts for Volatile Organic Compound Control in the 1990's; Paper presented at the 1990 Incineration Conference, San Diego, CA, May 14-18, 1990.

Johnson, L.D., Detecting Waste Combustion Emissions, Environ. Sci. Tech., 20, 223, 1986.

Keller, J.O., Gemmen, R.S., and Barr, P.K., Premixed Combustion in an Oscillating/Resonant Flow Field. Part I:Experimental Investigation, Proceedings of the 1990 ASME Winter Annual Meeting, Nov. 25-30, 1990, Dallas, Tx.

Kittrell, J.R., Quinlan, C.W., and Eldridge, J.W., Direct Catalytic Oxidation of Halogenated Hydrocarbons, Journal of the Air and Waste Management Association, 41, 1129-1133, 1991.

Koffskey, W.E., Lykins, B.W., GAC Adsorption and Infrared Reactivation: A Case Study, Journal AWWA, 82, No.1, 48-56, 1990.

Koszalka, D.P., Soodsma, J.F., and Bever, R.A., Ultrasonic Destruction of PCBs in Solids, Abstract from Symposium on Innovative Destruction Processes for Pollution Control, 1992.

Looney, B.B., Hazen, T.C., Kaback, D.S., Eddy, C.A., Full Scale Field Test of the In Situ Air Stripping Process at the Savannah River Integrated Demonstration Test Site (U), Westinghouse Savannah River Company Report WSRC-RD-91-22, June 29, 1991. 
Matthews, S. M., Environmental Remediation Using Intense Penetrating Bremsstrahlung, Summary of work performed under TTP No. 1506-31, Aug. 8, 1991.

Nimios, M.R.; Jacoby, W.A.; Blake, D.M.; Milne, T.A.,"Direct Mass Spectrometric Studies of the Destruction of Hazardous Wastes. 2. Gas-Phase Photocatalytic Oxidation of Trichloroethylene over $\mathrm{TiO}_{2}$ : Products and Mechanisms", Environ. Sci. Technol. 1993, 27, $732-740$

Nunez, C.M., G. H. Ramsey, W. H. Ponder, J.H. Abbott, L. E. Hamel, and P. H. Kariher, Corona Destruction: An Innovativc Control Technology for VOCs and Air Toxics, J. Air \& Waste Management, 43, 242-247, February, 1993.

Ollis, D.F., Pelizzetti, E., and Serpone, N., Photocatalyzed Destruction of Water Contaminants, Environmental Science and Technology, 25, 1522-1529, 1991.

Oxenford, J.L., and Lykins, B.W.Jr., Conference Summary: Practical Aspects of the Design and Use of GAC, Journal AWWA, 83, No.1, 58-64, 1991.

Palazzolo, M.A., Jamgochian, C.L., Steinmetz, J.I., and Lewis, D.L., Destruction of Chlorinated Hydrocarbons by Catalytic Oxidation, EPA/600/2-86/079, 1986.

Rinko, J., and M. Traister, Practical Considerations for the Selection of Pollution Control Equipment for VOC Emissions, Paper presented at the 81st Annual Air Pollution Control Association Meeting, June 19-24, 1988, Dallas, TX. (Paper may be obtained from O'Brien \& Gere Engineers, Inc., Syracuse, NY)

Rossabi, J., J.S. Haselow, 1991. Technology Status Report: Off-Gas Treatment Technologies for Chlorinated Volatile Organic Compound Air Emissions, WSRC-RP-910603.

Servais, P., Billen, G., Ventresque, C., and Bablon, G.P., Microbial Activity in GAC Filters at the Choisy-le-Roi Treatment Plant, Journal AWWA, 83, No.2, 62-68, 1991.

Speth, T.F., and Miltner, R.J., Technical Note: Adsorption Capacity of GAC for Synthetic Organics, Journal AWWA, 82, No.2, 72-75, 1990.

Sprung, J., 1991. Personnel Communication with Sandia National Laboratory. 
Steverson, E.M., Provoking a Firestorm: Waste Incineration, Environmental Science and Technology, 25, 1808-1814, 1991.

Strandberg, G.W., Donaldson, T.L., and Farr, L.L., Degradation of Trichloroethene and trans-1,2-Dichloroethylene by a Methanotrophic Consortium in a Fixed-Film, Packed-Bed Bioreactor, Environmental Science and Technology, 23, 1422-1425, 1989.

Takacs, L., and Moilanen, G. L., Simultaneous control of PCDD/PCDF, $\mathrm{HCl}$ and $\mathrm{NO}_{\mathbf{x}}$ emissions from municipal solid waste incinerators with Ammonia injection (1991). Journal of Air and Waste Management Association, 41, 716-722.

Varma, R., Nandi, S.P., and Cleaveland, D.C., Microwave-Assisted Chemical Process for Treatment of Hazardous Waste, DOE/HWP-28 ANL-87-20, 1987.

Varma, R., Nandi, S.P., and Katz, J.D., Detoxification of Hazardous Waste Streams Using Microwave-Assisted Fluid-Bed Oxidation, Materials Research Society Spring Meeting Symposium, April 16-21, 1990, San Francisco, CA.

Varma, R., and Nandi, S.P., Oxidative Degradation of Trichloroethylene Adsorbed on Active Carbons: Use of Microwave Energy, LA-UR--91-1552 DE91 013656, 1991.

Vancit, M.A., Howle, R.H., Herndon, D.J., and Shareef, S.A., Air Stripping of Contaminated Water Sources - Air Emissions and Controls, EPA-450/3-87-017, 1987.

Yosim, S.J., Kellogg, L.G., and Sudar, S., Molten Salt Destruction of HCB and ChlordaneBench and Pilot Scale Tests, Final Report EPA/600/2-84/148.

Wekhof, A., Treatment of Contaminated Water, Air and Soil With UV Flashlamps, Environmental Progress, 10, 241-247, 1991.

Zafiriou, O.C., Marine Organic Photochemistry Previewed, Marine Chemistry, 5, 497-522, (1977).

Wijmans, J.G., Kaschemekat, J., Davidson, J.E., and Baker, R.W., Treatment of OrganicContaminated Wastewater Streams by Pervaporation, Environmental Progress, 2, No.4, 262-268. 


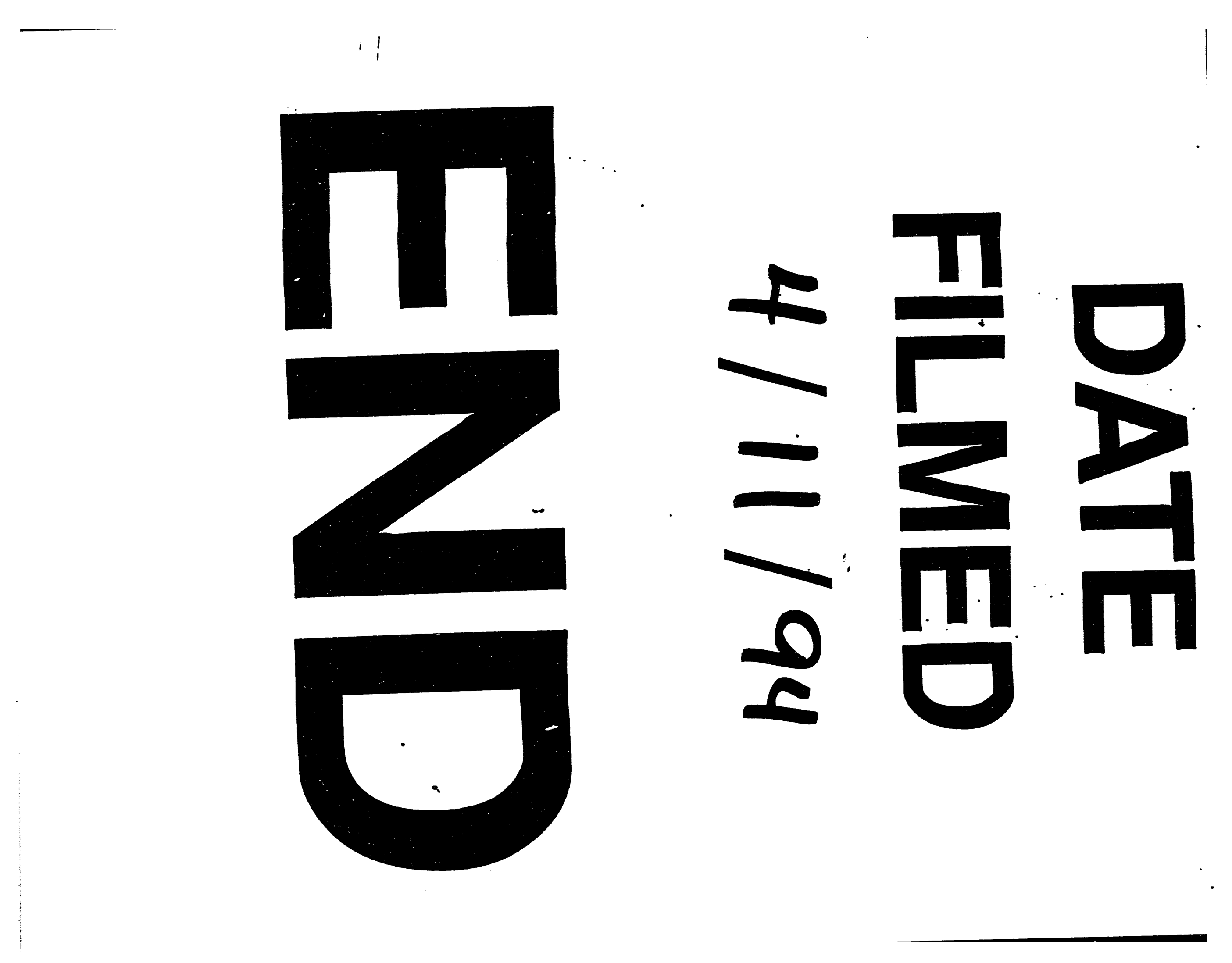


